\title{
Scalp Free Flap Reconstruction Using Anterolateral Thigh Flap Pedicle for Interposition Artery and Vein Grafts
}

\author{
Jun Hyung Park ${ }^{1}$, Kyung Hee Min ${ }^{1}$, Suk Chan Eun ${ }^{2}$, Jong Hoon Lee ${ }^{1}$, Sung Hee Hong ${ }^{1}$, \\ Chin Whan Kim ${ }^{1}$ \\ ${ }^{1}$ Department of Plastic and Reconstructive Surgery, Eulji General Hospital, Eulji University School of Medicine, Seoul; ${ }^{2}$ Department of Plastic \\ and Reconstructive Surgery, Seoul National University College of Medicine, Seoul, Korea
}

We experienced satisfactory outcomes by synchronously transplanting an artery and vein using an anterolateral thigh flap pedicle between the vascular pedicle and recipient vessel of a flap for scalp reconstruction. A 45-year-old man developed a subdural hemorrhage due to a fall injury. In this patient, the right temporal cranium was missing and the patient had $4 \times 3$ $\mathrm{cm}$ and $6 \times 5 \mathrm{~cm}$ scalp defects. We planned a scalp reconstruction using a latissimus dorsi free flap. Intraoperatively, there was a severe injury to the right superficial temporal vessel because of previous neurosurgical operations. A $15 \mathrm{~cm}$ long pedicle defect was needed to reach the recipient facial vessels. For the vascular graft, the descending branch of the lateral circumflex femoral artery and two venae comitantes were harvested.

The flap survived well and the skin graft was successful with no notable complications. When an interposition graft is needed in the reconstruction of the head and neck region for which mobility is mandatory to a greater extent, a sufficient length of graft from an anterolateral flap pedicle could easily be harvested. Thus, this could contribute to not only resolving the disadvantages of a venous graft but also to successfully performing a vascular anastomosis.

Keywords Scalp / Free tissue flaps / Vascular grafting
Correspondence: Kyung Hee Min Department of Plastic and Reconstructive Surgery, Eulji General Hospital, Eulji University School of Medicine, 68 Hangeulbiseong-ro, Nowon-gu, Seoul 139-711, Korea Tel: +82-2-970-8255

Fax: +82-2-978-4772

E-mail:mkh0226@eulji.ac.kr

This article was presented as a poster at the 68th Congress of the Korean Society of Plastic and Reconstructive Surgeons on November 4-7, 2010 in Seoul, Korea.

No potential conflict of interest relevant to this article was reported.

Received: 13 May 2011 • Revised: 22 Jun 2011 • Accepted: 27 Jun 2011

pISSN: 2234-6163 • elSSN: 2234-6171 • http://dx.doi.org/10.5999/aps.2012.39.1.55 • Arch Plast Surg 2012;39:55-58

\section{INTRODUCTION}

The essential factors of successful microvascular anastomosis include healthy vessels of reasonable size, good outflow tracts, and technically perfect anastomosis. In addition, an appropriate length of the vascular pedicle must be selected to be certain that the anastomosis is made without tension [1].

In reconstruction of head and neck regions in particular, where the mobility of the head and neck can cause tension and kinking of the anastomotic site, great circumspection is needed in examining the geometry of the vascular pedicle. In this respect, a free flap which is transferred to the head and neck region is markedly different from those used for the reconstruction of the extremities, where immobilization has already been achieved [2].

Moreover, a prior ipsilateral radical neck dissection will severely limit the availability of recipient vessels. Furthermore, advanced

Copyright $\odot 2012$ The Korean Society of Plastic and Reconstructive Surgeons

This is an Open Access article distributed under the terms of the Creative Commons Attribution Non-Commercial License (http://creativecommons.org/

licenses/by-nc/3.0/) which permits unrestricted non-commercial use, distribution, and reproduction in any medium, provided the original work is properly cited.

www.e-aps.org 
age and prior radiation therapy, which may cause atherosclerosis, can also limit their availability. Finally, direct tumor extension from the primary tumor or a regional metastasis can restrict the surgeon's choice [2].

Under such circumstances, up to the present, to achieve a tension-free vascular pedicle that will withstand the full range of motion of the head and neck without stress, vein grafts from the saphenous or cephalic system are commonly considered the most versatile and readily available for an interposition graft [2-4] .

However, high-flow vein grafts, such as from the cephalic and saphenous vein, have higher risks of acute thrombosis and hemorrhagic complications due to hyperperfusion [5].

At our institution, we obtained satisfactory treatment outcomes by synchronously transplanting the artery and vein using an anterolateral thigh flap pedicle at the defect site between the vascular pedicle and recipient vessel of a flap in latissimus dorsi free flap reconstruction for scalp free flap reconstruction. Here, we report our treatment outcomes with a review of the literature.

\section{CASE}

The current case is a 45-year-old man who developed a subdural hemorrhage due to an injury from a fall, and who had main-

\section{Fig. 1. Preoperative view of the patient}

There was a loss of the right temporal area of the cranium and a scalp defect of $4 \times 3 \mathrm{~cm}$ in the posterior area and $6 \times 5 \mathrm{~cm}$ in the anterior area, each of which were tunneled and connected. In addition, there was an exposure of the artificial dura graft that had been previously applied surgically, which was accompanied by a chronic infection.

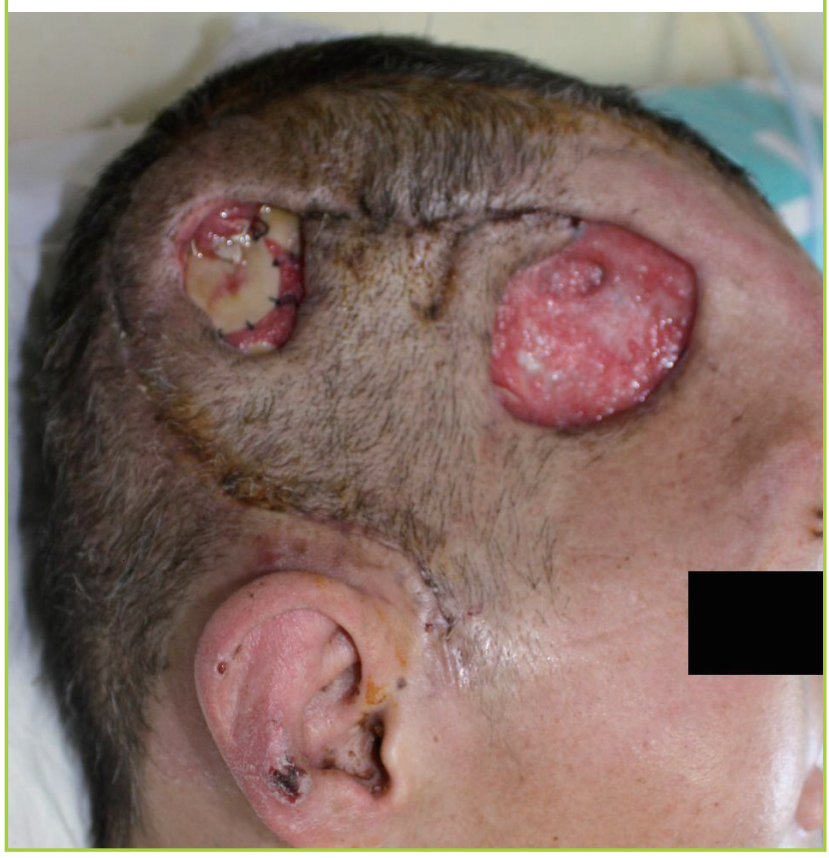

tained a comatose state for more than three months following craniotomy. In addition, the patient also had a loss of the right temporal area of the cranium and a scalp defect $4 \times 3 \mathrm{~cm}$ in size in the posterior area and $6 \times 5 \mathrm{~cm}$ in size in the anterior area, each of which were tunneled and connected. There was an exposure of the artificial dura graft that had been previously performed, which was accompanied by a chronic infection (Fig. 1). To cover this large scalp defect vulnerable to infection, we needed a broad, not thin, and blood flow-rich muscle flap; thus we used a latissimus dorsi muscle free flap. Intraoperative findings showed that there was a severe injury to the right superficial temporal vessel because neurosurgical operations had been performed several times before and there were no available according recipient vessels. The right facial artery and vein were prepared as a recipient vessel. Consequently, there was a defect of $15 \mathrm{~cm}$ in length between the facial vessels and the pedicle of a latissimus dorsi muscle free flap, which was harvested. We used a vascular pedicle of an anterolateral thigh flap as an interposition artery and vein graft. For the vascular graft, an incision was made on the right thigh. Then, the descending branch of the lateral circumflex femoral artery and two venae comitantes, a vascular pedicle of the anterolateral thigh flap, whose length was $15 \mathrm{~cm}$, were concurrently harvested. This was followed by an end-to-end anastomosis of the vascular pedicle, graft vessel, and recipient vessel of a free flap in the corresponding order (Figs. 2, 3 ). Insetting of the muscle flap was done for the defect site, on which a split thickness skin graft was performed.

\section{Fig. 2. Flap insetting}

Insetting of the latissimus dorsi free flap was performed for the defect site. Then the defect of $15 \mathrm{~cm}$ in length was made in the area between the vascular pedicle and recipient vessel of a latissimus dorsi free flap which was harvested.

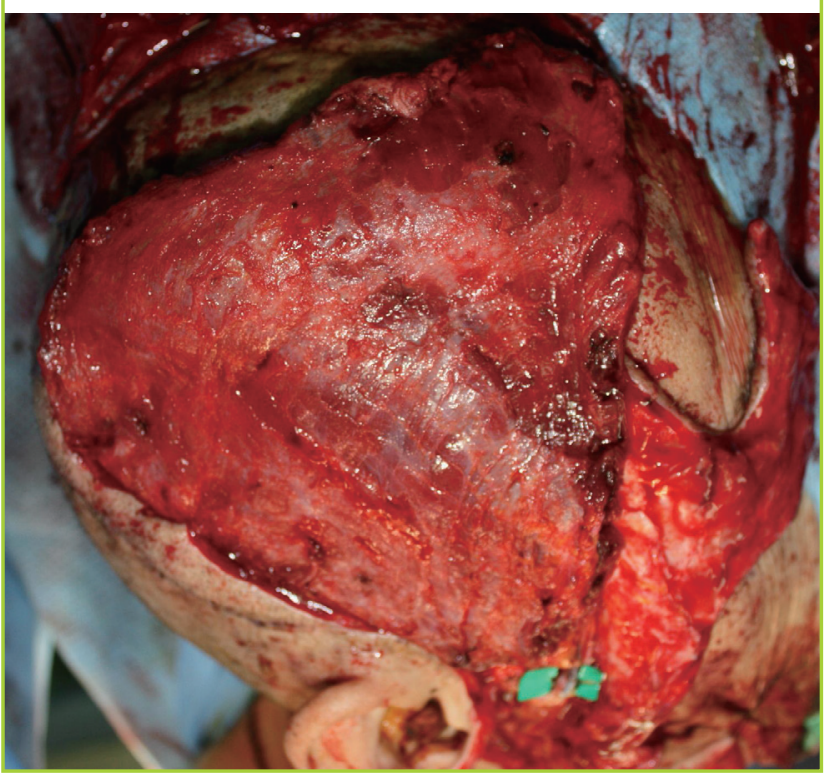




\section{Fig. 3. Pedical anastomosis}

The descending branch of the lateral circumflex femoral artery, a vascular pedicle of the anterolateral thigh flap, and two $15 \mathrm{~cm}$ venae comitantes were concurrently harvested. These were connected by an end to end anastomosis of the vascular pedicle, graft vessel and recipient vessel of a free flap in corresponding order.

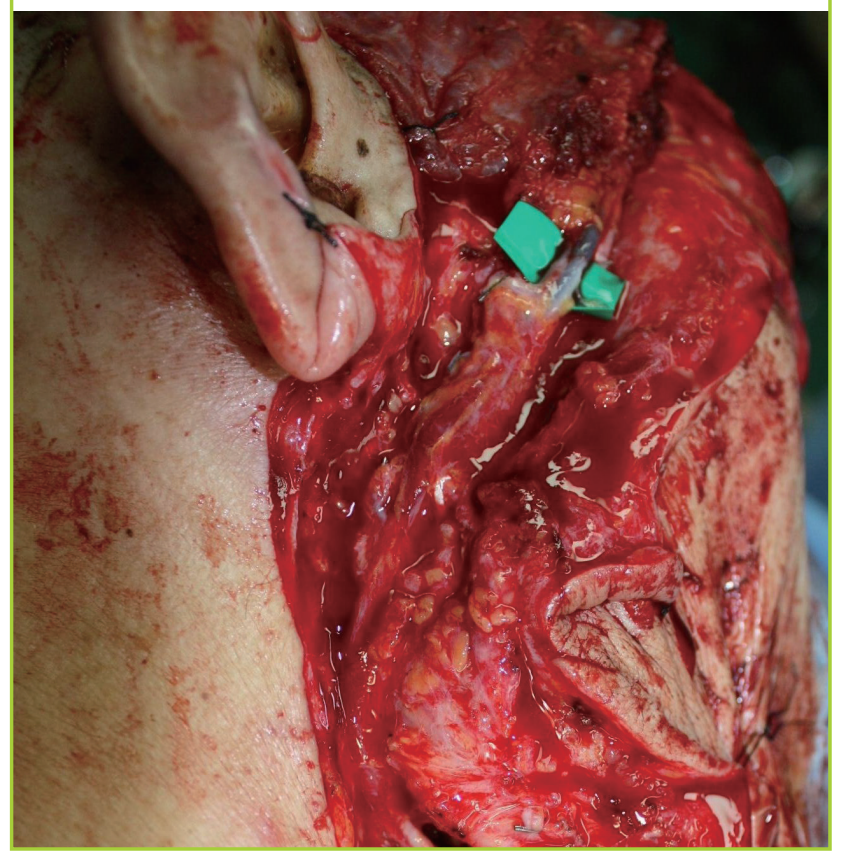

Postoperatively, all the flaps survived well and the skin graft was successful. Besides, there were no further infection signs (Fig. 4). Furthermore, there were no notable complications at the donor site of the flap and the vessel, which suggested a successful healing process (Fig. 5).

\section{DISCUSSION}

Careful concern about recipient vessel selection, geometry of the vascular pedicle, and the techniques of leakproof anastomosis can contribute to obtaining successful treatment outcomes of microvascular surgery and avoiding some of the potential complications that may occur [2].

The situations in which interposition graft usage is considered include a short pedicle, significant size mismatch, tension at the site of anastomosis, and the need to shift the anastomotic site away from an injured area [1]. Arterial homografts, autogenous vein grafts, and synthetic prostheses each have their own properties, although vein grafts are used more commonly because they are more versatile and easily available [3]. According to some studies, however, high-flow vein grafts using cephalic and saphenous veins have higher risks of developing acute thrombosis and hemorrhagic complications due to hyperperfusion [5].

According to a review of various cardiac studies, the patency
Fig. 4. Photograph 4 weeks postoperatively

All flaps survived well and the skin graft was successful. In addition, there were no further signs of infection.

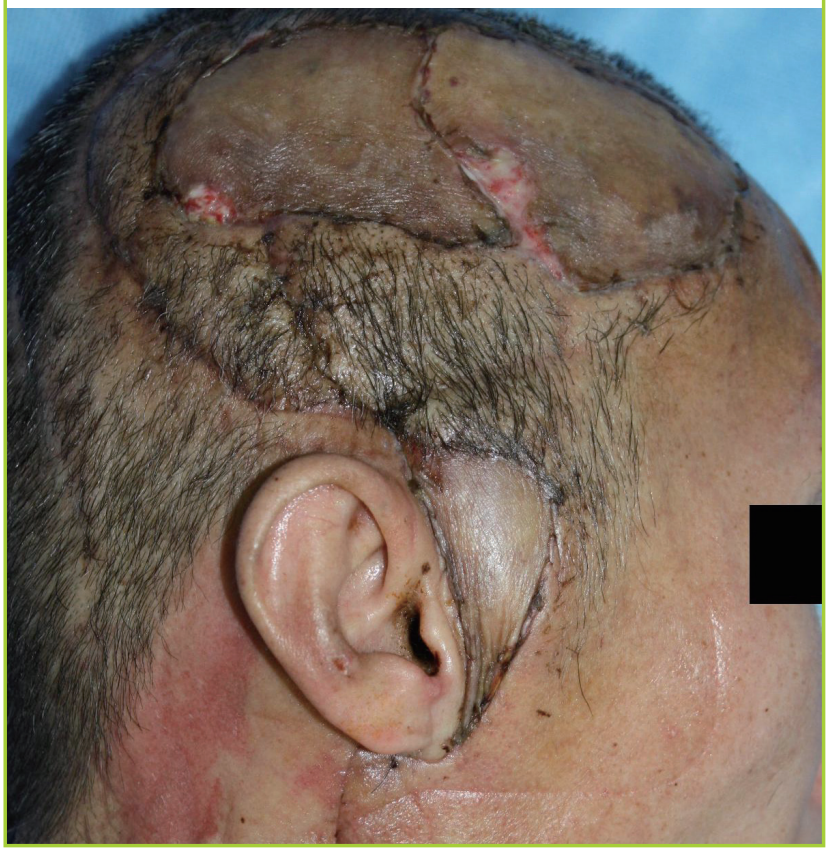

Fig. 5. Photograph 10 months postoperatively

A $21 \mathrm{~cm}$ linear scar was left without any complications at the donor site of the vessel graft, on the right lateral thigh. There were no notable complications at the donor site of the flap and skin graft.

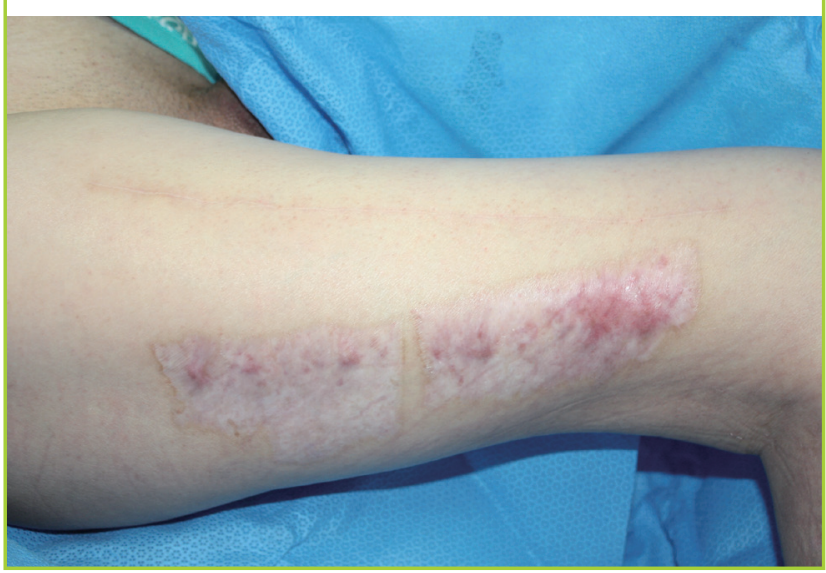

rates of arterial conduits and the low incidence of spasm are far superior to those of vein grafts [6,7]. Based on the literature, the arterial graft has some distinctive advantages, such as low incidence of arteriosclerosis, presence of elastic structure in the media, its adjustment to the same arterial hemodynamic characteristics and the biochemical environment [7]. Recently, in light of these advantages, the descending branch of the lateral circumflex femoral artery has already been utilized for vascular bypass grafting in the field of neurovascular and cardiac surgery $[7,8]$. Neurovascular surgeons reported a case in which the descend- 
ing branch of the lateral circumflex femoral artery was utilized as a high-flow conduit for an extracranial-intracranial bypass operation [8].

The length of descending branch of the lateral circumflex femoral artery depends on the length of the thigh with a mean value of $14.3 \pm 2.3 \mathrm{~cm}$ (range, 12.6 to $17.4 \mathrm{~cm}$ ). Besides, the diameter of the first 12 to $15 \mathrm{~cm}$ is between $2.5 \mathrm{~mm}$ (proximal) and 1.5 $\mathrm{mm}$ (distal) and the two venae comitantes have diameters slightly larger than the artery. As shown above, not only is the vessel caliber large and appropriate for microsurgical anastomosis in head and neck reconstruction, but also the sufficient length of the vascular pedicle increases its availability for the interposition graft. Even the harvesting of the artery could be performed easily in a short time with a mean value of $18 \pm 4$ minutes [7]. The donor site defect can be closed without causing a notable scar. In addition, the wound resulting from the harvesting of an anterolateral flap pedicle usually heals rapidly and local infection and compartment syndrome are rarely observed [7].

To our knowledge, the current case indicates that the artery and vein should be concurrently grafted using an anterolateral flap pedicle with a similar diameter to the facial blood vessels, with which a sufficient length of graft could be easily harvested, if an interposition graft is needed in the reconstruction of the head and neck region, for which the mobility is mandatory to a greater extent than other body areas. Thus, this could contribute to not only resolving the disadvantages of a venous graft but also successfully performing a vascular anastomosis.

\section{REFERENCES}

1. Mathes SJ, Hentz VR. Plastic surgery. 2nd ed. Philadelphia, PA: Saunders Elsevier; 2006.

2. Urken ML, Cheney ML, Sullivan MJ, et al. Atlas of regional and free flaps for head and neck reconstruction. New York, NY: Raven Press; 1995.

3. Baker SR. Microsurgical reconstruction of the head and neck. New York, NY: Churchill Livingstone; 1989.

4. Chang KP, Lee HC, Lai CS, et al. Use of single saphenous interposition vein graft for primary arterial circuit and secondary recipient site in head and neck reconstruction: a case report. Head Neck 2007;29:412-5.

5. Friedman JA, Piepgras DG. Current neurosurgical indications for saphenous vein graft bypass. Neurosurg Focus 2003; 14:e1.

6. Suma H. Arterial grafts in coronary bypass surgery. Ann Thorac Cardiovasc Surg 1999;5:141-5.

7. Fabbrocini M, Fattouch K, Camporini G, et al. The descending branch of lateral femoral circumflex artery in arterial CABG: early and midterm results. Ann Thorac Surg 2003; 75:1836-41.

8. Baskaya MK, Kiehn MW, Ahmed AS, et al. Alternative vascular graft for extracranial-intracranial bypass surgery: descending branch of the lateral circumflex femoral artery. Neurosurg Focus 2008;24:E8. 